\title{
Stormorken-Sjaastad-Langslet syndrome
}

INSERM

\section{Source}

INSERM. (1999). Orphanet: an online rare disease and orphan drug data base.

Stormorken-Sjaastad-Langslet syndrome. ORPHA:3204

Stormorken-Sjaastad-Langslet syndrome is characterized by thrombocytopathy,

asplenia, miosis, muscle fatigue, migraine, dyslexia, and ichthyosis. It has been described

in six members of one family. It is transmitted as an autosomal dominant trait. 